\title{
TIMORIZAÇÃO DA GEOGRAFIA ESCOLAR: TECENDO INTERLOCUÇÕES SOBRE CURRÍCULO, CULTURA E TERRITÓRIO*
}

\author{
TIMORIZATION OF SCHOOL GEOGRAPHY: MAKING \\ INTERLOCATIONS ON CURRICULUM, CULTURE AND \\ TERRITORY
}

\author{
Vanessa Lessio Diniz ${ }^{* *}$ \\ Vicente Paulino ${ }^{* \star}$ \\ Rafael Straforini ${ }^{* \star \star}$
}

\begin{abstract}
RESUMO: Neste artigo abordamos a relação entre currículo, cultura e território, dentro do contexto da Geografia escolar em Timor-Leste, problematizando a colonialidade presente em diferentes momentos da constituição dessa disciplina. Com base na perspectiva pós-crítica e pós-estruturalista da Teoria do Discurso de Ernesto Laclau, compreendemos que a elaboração e a implementação de um currículo estão carregadas de disputas discursivas entre contextos políticos, concepções institucionais e atores sociais envolvidos nesse processo. Metodologicamente, a partir de um levantamento documental, de interlocuções com profissionais da educação timorense e da análise do Manual do Aluno de Geografia ( $10^{\circ}$ ano de escolaridade), verificamos que esta disciplina, historicamente, esteve voltada para atender à manutenção da colonização portuguesa, da ocupação territorial indonésia, e atualmente, está ligada a uma ótica geográfica estrangeira, por meio de uma reforma curricular conduzida predominantemente pela Cooperação Portuguesa. Consideramos assim, a importância da timorização da Geografia escolar, como um caminho decolonial, que contribui para que os professores timorenses sejam autônomos nos processos de elaboração, implementação e avaliação curricular, possibilitando a construção de outras formas de
\end{abstract}

* Este artigo resulta da pesquisa de doutorado da primeira autora, intitulada "Currículo e sentidos de Geografia em Timor-Leste: disputas na significação da identidade nacional timorense", defendida no programa de Pós-Graduação em Geografia da Universidade Estadual de Campinas (Unicamp), sob orientação do prof. Rafael Straforini. Pesquisa realizada com apoio da Coordenação de Aperfeiçoamento de Pessoal de Nível Superior (CAPES) - Código de Financiamento 001.

** Doutora em Geografia pela Universidade Estadual de Campinas (Unicamp). Professora do curso de Licenciatura em Geografia da Universidade Federal do Tocantins (UFT). Contato: vanessalessiodiniz@gmail.com.

*** Doutor em Estudos de Literatura e Cultura pela Faculdade de Letras da Universidade de Lisboa (Portugal). Professor Convidado da Universidade Nacional Timor Lorosa'e (Timor Leste). Contato: vicentepaulino123@gmail.com.

${ }^{* * * *}$ Doutor em Geografia pela Universidade Federal do Rio de Janeiro (UFRJ). Professor do curso de Geografia e da Pós-Graduação em Geografia da Universidade Estadual de Campinas (Unicamp). Contato: strafo@unicamp.br. 
representações, sentidos e saberes geográficos diante de conteúdos curriculares prescritos.

Palavras-chave: Ensino de Geografia. Currículo. Práticas espaciais. Decolonialidade. Timor-Leste.

\begin{abstract}
In this article we approach the relationship between curriculum, culture and territory, within the context of school geography in East Timor, problematizing the coloniality present in different moments of constitution of this discipline. Based on the post-critical and post-structuralist perspective of Ernesto Laclau's Theory of Discourse, we understand that the development and implementation of a curriculum are fraught with discursive disputes between political contexts, institutional conceptions and social actors involved in this process. Methodologically, based on a documentary survey, interlocutions with Timorese education professionals and the analysis of the Geography Student Manual (10th year of schooling), we verify that this discipline, historically, has been geared to meet to the maintenance of Portuguese colonization, of the Indonesian territorial occupation, and currently, it is linked to a foreign geographical perspective, through a curricular reform conducted predominantly by Portuguese Cooperation. We consider, therefore, the importance of the timorization of school Geography, as a decolonial path, which may contribute for Timorese teachers to be protagonists in the processes of elaboration, implementation and curriculum evaluation, enabling the construction of other forms of representations, meanings and geographic knowledge in the face of prescribed curriculum content.
\end{abstract}

Keywords: Geography teaching. Curriculum. Space practices. Decoloniality. East Timor.

\title{
DIÁLOGOS INICIAIS
}

Ao refletirmos sobre o papel da Geografia escolar na contemporaneidade, pensando na sua contribuição para a formação de diferentes sujeitos sociais em um mundo globalizante e globalizado, e consequentemente desigual, evidenciase a necessidade da discussão sobre o contexto de produção dos currículos dessa disciplina, articulada a uma atenta observação sobre as representações culturais e territoriais presentes em documentos curriculares, que agem no processo de significação e na consolidação de significados sobre um determinado povo, lugar, território e nação.

Com base em Haesbaert e Porto-Gonçalves (2006), é possível dizer que fomos habituados a pensar e sentir o mundo como se fosse natural a existência de uma geografia que conhecemos, ou seja, essa forma de organização do espaço geográfico em Estados, com suas fronteiras territoriais nítidas e reconhecidas, assim como suas relações bem definidas. Porém, esta 
configuração é sempre provisória e contingencial, estando longe de ser um produto natural, "ao contrário, trata-se de uma invenção histórica europeia que, depois, se generalizou para o mundo como parte do colonialismo e do imperialismo" (p. 13).

Nessa mesma perspectiva, como aborda Amílcar Cabral (1979), considerado o "pai" da independência de Guiné-Bissau e Cabo Verde contra o colonialismo português e uma das grandes referências da resistência timorense - uma "libertação nacional" não produz automaticamente uma "descolonização das mentes", uma vez que, após a independência, a luta pelas formas de gestão do saber e criação intelectual constitui-se por novas relações de poder que atravessam as fronteiras da soberania nacional. Mesmo com o fim do colonialismo, os padrões de organização e comportamentos, assim como conceitos e categorias analíticas eurocêntricas, ainda hoje se imperam como naturais, isto é, tornaram-se normas e práticas discursivas universais e se transformaram em modelo de civilização a ser almejado por todo planeta (MIGNOLO, 2003; MALDONADO-TORRES, 2007).

O geógrafo Milton Santos, desde a década de 70 do século XX, já mostrava a importância do trabalho do geógrafo partindo do/no terceiro mundo (SANTOS, 2013), como crítica a uma geografia tradicional fundada no pensamento europeu e nas pesquisas meramente aplicadas aos países periféricos. No início do século XXI, ao analisar a globalização como o resultado "perverso" da vontade de integrar mercados segundo um discurso único, esse autor escreveu um manifesto sobre a necessidade do papel ativo da Geografia como possibilidade de intervenção nos processos de transformação social, uma vez que, "a geografia deve estar atenta para analisar a realidade social total a partir de sua dinâmica territorial” (SANTOS, 2000, p. 108). Recentemente, Rogério Haesbaert (2021, p. 23) nos apresenta de forma sistematizada as contribuições do pensamento de(s)colonial ${ }^{1}$ para a Geografia, apontando a necessidade de um "giro espacial/territorial" que transforme "não apenas o

\footnotetext{
1 Segundo Haesbaert (2021), o termo "de(s)colonial" (e suas derivações) foi utilizado em alguns capítulos de seu livro com o " $s$ " entre parênteses sempre que foi feita alusão ao conjunto de pensamentos que, sob ambas designações - decolonial ou descolonial- visa de modo prioritário a combater a "colonialidade" ainda profundamente arraigada em nossas sociedades.
} 
âmbito teórico, do pensamento, mas, fundamentalmente, as práticas insurgentes inovadoras que se engajem de fato por uma nova ordem socioeconômica, política e cultural em nossos espaços de vida - e vida tanto humana quanto nãohumana-".

Nessa direção, sobre o papel ativo e decolonial da Geografia escolar em Timor-Leste, é possível identificar uma disciplina de passado colonial, que ainda hoje apresenta sentidos discursivos de sujeitos europeus e da Europa como centro do mundo, como a padronização de um jeito de ser, pensar e existir, expressando-se na materialização dos currículos produzidos por profissionais portugueses, ou seja, uma Geografia escolar que pouco avança ou contribui para a construção de práticas espaciais insurgentes² que propiciem a emancipação dos sujeitos timorenses. Consideramos assim, a importância da timorização da Geografia escolar, como um caminho decolonial, que pode contribuir para que os professores timorenses sejam autônomos nos processos de elaboração, implementação e avaliação curricular, possibilitando a construção de outras formas de representações, sentidos e saberes geográficos diante de conteúdos curriculares prescritos.

Essa timorização pode ser entendida como o diálogo permanente e indissociável entre conteúdos geográficos, o tempo-espaço de Timor-Leste, e as cosmogonias (o lulik) das tradições timorense, ampliando a visão de mundo dos(as) estudantes, para que os(as) mesmos(as) conheçam e reconheçam seu papel numa sociedade hoje tecnológica-científica-informacional e em uma economia e cultura globalizada (DINIZ; MA'AVERU, 2019; DINIZ, 2019), porém (re)conectados com os aspectos míticos e tangíveis da diversidade étnica, cultural e linguística desse território.

\footnotetext{
2 Segundo Souza (2013), as práticas espaciais devem ser entendidas como práticas sociais em que a espacialidade se torna um componente nítido e destacado de forma de organização, do meio de expressão e/ou dos objetos a serem alcançados "toda prática espacial, assim como, mais amplamente toda prática social é uma ação (um conjunto estruturado de ações) inscrita nos marcos de relações sociais" (p. 241). Para o mesmo autor, as práticas espaciais insurgentes, remetem à ideia de práxis "visando a transformação da realidade, politicamente falando. [...] Ação com sentido, pois é isto que a práxis é: uma ação dotada de sentido. No caso das práxis emancipatórias, um sentido que é inerentemente crítico em relação ao status quo social heterônomos, em graus e de modos variados" (ibidem, p.250).
} 
Destacamos, que este trabalho é fruto de uma experiência coletiva transversa por leituras e conversas com diferentes interlocutores, que contribuíram de modo significativo para as muitas impressões, questionamentos e análises que serão apresentadas. As histórias orais dos interlocutores timorenses estão presentes na fundamentação de nossas análises, já que foram de extrema importância para compreender lacunas difíceis de serem preenchidas sobre o contexto da Geografia escolar timorense. Paulino e Apoema (2016), enfatizam que a base e o fundamento dos saberes e conhecimentos timorenses estão sob a guarda das tradições orais - por meio de narrativas, de poemas, de hamulak sira (orações), de canções e inclusive das próprias narrativas de vida.

Assim, em tempos de neoliberalismo globalizante, no qual opera a forte alienação e imposição da cultura hegemônica (com forte herança colonial) do homem/branco/cristão/europeu, se faz necessária desafiar a lógica da desigualdade epistêmica e, assim, interromper os discursos e práticas hegemônicos no campo da Geografia escolar. Vale ressaltar, que por meios das representações, os significados são produzidos e compartilhados entre os membros de uma sociedade (HALL, 2016), e tentam se fixar como discursos universais ou hegemônicos (LACLAU, 2013), já que representar envolve o uso da linguagem, de textos, de símbolos, de signos e de imagens, que se apresentam como realidades, verdades e valores atribuídos a um determinado grupo social, a um povo e a um território.

Dessa maneira, este artigo tem como objetivo compreender as relações entre currículo, cultura e território, dentro do contexto da Geografia escolar de Timor-Leste, problematizando a colonialidade presente em diferentes momentos da constituição dessa disciplina. Para tanto, dividimos o texto em três momentos, primeiramente, teceremos um dialogo a partir dos referenciais teóricometodológicos que direcionam nosso entendimento sobre currículo, cultura e território. No segundo momento, apresentaremos a partir de fragmentos documentais e de enunciados de interlocutores timorenses, um histórico da Geografia escolar em Timor-Leste. Por fim, buscaremos discutir os indícios discursivos de colonialidade presentes no Manual do Aluno de Geografia do $10^{\circ}$ 
ano do Ensino Secundário Geral (ESG), evidenciando a necessidade da timorização da Geografia escolar nesse país.

\section{INTERLOCUÇÕES SOBRE CURRÍCULO, CULTURA E TERRITÓRIO COM APORTES NA TEORIA DO DISCURSO E NO PENSAMENTO DECOLONIAL}

Alguns autores que dialogamos (SANTOS (2000), LOPES (2013), BARBOSA; DINIZ; PAULINO (2020) discorrem que os processos de globalização buscam impor, a todos os lugares, uma única racionalidade sobre as esferas política, econômica, cultural e também educacional, na qual passamos a vivenciar uma internacionalização das políticas educacionais, em que agências internacionais, financeiras ou não, formulam recomendações sobre políticas públicas para países emergentes ou em desenvolvimento. Com base em Dale (1998), entendemos que os quadros regulatórios nacionais são, agora, em maior ou menor medida, moldados e delimitados por forças supranacionais e político-econômicas nacionais, muitas vezes por vias indiretas, por meio de práticas de influência complexas sobre o Estado e sobre o modo de regulação. Assim, a globalização tem os seus mais óbvios e importantes efeitos sobre os sistemas educativos nacionais.

Nessa direção, em nossas pesquisas, temos considerado o currículo de Geografia uma construção sócio-discursiva, que apresenta as intencionalidades de uma política educacional vigente a qual desempenha o papel de informar e formar sujeitos, difundindo o que uma dada hegemonia discursiva considera como verdade sobre um determinado assunto. Entendemos essa hegemonia como "uma relação em que um conteúdo particular assume, num certo contexto, a função de encarnar uma plenitude ausente" (LACLAU, 2002, p. 122).

O currículo sendo uma construção sócio-discursiva, pode ser entendido como uma arena de todos os tipos de mudanças, interesses e relações de dominação (GOODSON, 1995), não se tratando apenas de uma seleção neutra de conteúdos. Nesse sentido, propostas curriculares ancoradas nas disciplinas escolares deixam sempre à mostra diferentes dimensões de Estado, como a econômica, a política e a cultural, representando os interesses substanciais de 
uma hegemonia política - que sempre será contingencial e provisória (LOPES, 2011).

Dessa forma, para compreendermos a relação entre as políticas curriculares, seus impactos no território timorense e as significações discursivas sobre as culturas e as identidades - considerando toda a complexidade da implementação de um novo documento curricular em escala nacional - nosso olhar analítico partirá da Teoria do Discurso desenvolvida por Ernesto Laclau. Para este autor, o discurso não está apenas relacionado à fala ou à escrita, mas a qualquer prática de significação social, ou seja, o discurso pode ser considerado "uma unidade complexa de palavras e ações, de elementos explícitos e implícitos, de estratégias conscientes e inconscientes" (BURITY, 2014, p. 66).

Neste trabalho, a Teoria do Discurso será utilizada como referencial teórico-metodológico, sendo considerada como uma ferramenta para compreensão do social, cujo entendimento se dá a partir de ordens discursivas. Serão instrumentalizadas as categorias ponto nodal, cadeias articulatórias, hegemonia e significante vazio ${ }^{3}$ para fim de análise dos discursos presentes e extraídos das superfícies textuais dos documentos curriculares e das entrevistas com nossos interlocutores.

Esse referencial teórico-metodológico pode permitir a identificação de contradições com uma lógica reprodutiva, pois "busca superar a separação entre a proposta [curricular] e sua implementação, bem como entre estrutura e agência, por meio de abordagens discursivas" (LOPES; MACEDO, 2011, p. 235). Permitindo romper com abordagens que apenas enfatizam a verticalização dos movimentos de produção, dando destaque aos processos de tradução que as políticas, concebidas como discursos, sofrem nos diferentes contextos de produção e de prática curricular (COSTA; PEREIRA, 2013). Essa abordagem favorece a indagação sobre as relações entre contextos de produção de currículos, sujeitos produtores, contextos de apropriação curricular e sujeitos

\footnotetext{
${ }^{3}$ Estas categorias são explorados no livro Emancipação e diferença, com destaque para os capítulos "Universalismo, particularismo e a questão da identidade", "Por que os significantes vazios são importantes para a política?" e "Sujeito da Política e política do sujeito" (LACLAU, 2011, p. 47-105).
} 
presentes nos currículos, revelando também o quanto a elaboração e implementação de um currículo pode ser complexa e ir muito mais além da proposta curricular que o sustenta.

Os processos de significação discursiva acontecem por meio de um sistema articulatório de cadeias de diferença e de equivalência, que disputam sentidos criados no movimento de luta política. Diferentes demandas, que estão dispersas no campo da discursividade, são ordenadas em uma cadeia de equivalência. Nessa perspectiva discursiva, entendemos que o ordenamento das demandas políticas acontece em função de um exterior constitutivo, uma diferença interpretada como ameaça comum a ser combatida, ou um outro opressor. Tal momento possibilita que demandas diferenciadas de um meio social possam abrir mão de seus conteúdos particulares para se incorporarem em uma articulação de equivalência que aspira à hegemonia (COSTA; PEREIRA, 2013, p. 296).

Segundo Laclau (2011), essa hegemonia ${ }^{4}$ consiste em um processo permanente de disputa, cujo objetivo é a fixação de determinados significados particulares, desejando que eles possam representar a totalidade. Entretanto, a fixação desses sentidos será sempre contingencial e provisória, e acontecerá a partir de determinadas condições específicas. A constituição de uma cadeia de equivalência para a formação de um discurso hegemônico se torna possível quando a articulação de demandas diferenciais se dá em torno de pontos nodais, ou seja, pontos de interseções contra os quais as identidades opostas a eles se unem, gerando a sensação de solidariedade (LOPES, 2011).

Dessa forma, compreendemos que o discurso é um movimento constante de disputa de significação, e se torna hegemônico quando um ponto nodal fecha a cadeia de significação em uma dada formação discursiva; quando um ou mais discursos particulares passam a se expressar como discurso universal. Contudo, neste trabalho, olharemos para o currículo como "um processo de produção de

\footnotetext{
4 "Tal concepção de discurso retira da hegemonia o sentido de algo imutável, incontestável e intransponível uma vez fixado. Assim, um dado sentido discursivo curricular só é permanência entendida aqui como um discurso hegemônico - em um tempo " $x$ " enquanto outros discursos ou pautas exteriores permanecerem contrárias ou dissonantes a ele, ou seja, o que se revela como discursos de mudança e de permanência são identidades discursivas próprias ou particulares e pouco conciliáveis" (STRAFORINI, 2016, p. 169).
} 
sentidos discursivos, sempre híbridos, que nunca cessa e que, portanto, é incapaz de produzir identidades [monolíticas]. O que ele produz é diferença pura, adiamento do sentido e, portanto, necessidade incessante de significação" (LOPES; MACEDO, 2011, p. 227). O currículo, em nossa perspectiva, se apresenta como um espaço-tempo de disputas, de busca por exercício de poder e territorialização discursiva (MACEDO, 2006), que se materializa em textos, práticas, arranjos, entre outros.

O currículo configura-se como um campo de disputas para obtenção do poder de seu discurso, a fim de legitimar visões específicas de mundo, como uma arena política (SILVA, 1996), assim, um currículo formal pode ser entendido como o reflexo das visões de grupos dominantes. Nesta arena, ocuparam espaço privilegiado no processo de produção do currículo de Geografia do Ensino Secundário Geral de Timor-Leste um grupo de profissionais portugueses da educação, ao passo que os professores da educação básica e da comunidade de Timor Leste foram secundarizados.

Apoiados em Santos e Meneses (2009), entendemos também que o currículo é organizado e estruturado com base nos pressupostos da ciência moderna, a qual é resultado de uma intervenção colonialista epistemológica baseada na força, com características políticas, econômicas e militares atreladas ao capitalismo moderno imposto aos povos e culturas não ocidentais e não cristãos.

A dimensão epistemológica presente no currículo se traduz na permanência do colonizar, na medida em que é imposta uma única episteme, na qual os saberes locais, em muitos casos não escritos, mas orais - representados pelos conhecimentos, valores, crenças, costumes, atitudes, cosmovisão, organização do trabalho etc. - não entram na seleção, organização e materialização dos conteúdos escolares (MUNSBERG; FUCHS; SILVA, 2019). Desse modo, utilizaremos também aportes dos estudos pós-coloniais e do pensamento decolonial para identificar indícios de colonialidade, ou seja, identificar nos documentos analisados e nas experiências vivenciadas pelos nossos interlocutores essa forma de conceber os conteúdos geográficos e as representações como uma construção discursiva neutra e natural. 


\section{GEOGRAFIA ESCOLAR DE TIMOR-LESTE: DO PASSADO COLONIAL AO PRESENTE DA COLONIALIDADE}

Refletir sobre a institucionalização da disciplina de Geografia em TimorLeste não é uma tarefa fácil, uma vez que o sistema educacional desse país passou por períodos de grande complexidade, derivando de intervenções externas às verdadeiras demandas educacionais locais. Silva (2015, p. 122) discorre que, na condição de um país pós-colonial, o sistema de educação timorense ainda hoje é afetado pelas heranças dos diferentes sistemas de educação coloniais, podendo ser caracterizado por uma triangulação entre "a herança colonial, a política de formação do Estado e a realidade da globalização". Sobre essa herança colonial na Geografia escolar timorense, podemos dizer que o sistema educacional no período português configurava-se como uma espécie de "espelho destorcido"5 do ensino da metrópole, "sendo implementado um currículo completamente ocidental, sendo uma educação de elite e sem acesso à educação pública em massa" (FONSECA, 2010, p. 17).

Esse fato pôde ser confirmado na busca documental realizada no Arquivo Nacional de Timor-Leste, no qual encontramos uma Conta de Responsabilidade ${ }^{6}$, ou seja, uma prestação de contas sobre a compra de materiais escolares. Essa conta acusava gastos com a compra de Mapas de Portugal Continental e Ultramarino e Mapa da América, não havendo a compra de Mapas da Ásia ou Sudeste Asiático.

Outro indício importante encontrado no Arquivo Nacional desse país, que também evidencia o ensino de uma geografia portuguesa, foi a prova do Exame de admissão aos Institutos Industriais - Geografia e História ${ }^{7}$ para a entrada no

\footnotetext{
${ }^{5}$ Consideramos como "espelho destorcido" e não como cópia fiel, pois a partir dos referenciais teóricos-metodológicos deste trabalho, entendemos que mesmo Portugal implementando em Timor-Leste o currículo utilizado na metrópole, este era ressignificado nas ações escolares cotidianas, ou seja, não era puramente espelhado, podendo até ser um espelho ondulado ou deformado que reproduz imagens também deformadas. Além do mais, como Fanon (1968) alerta, nunca foi de interesse do colonizador transformar a colônia em cópia fiel da metrópole. ${ }^{6}$ Conta de Responsabilidade - Documento: Administração Portuguesa em Timor-Leste, Série: Instituição Pública e Educação e Escola, Caixa 1 - Modelo III-B, TL AN TP AC IPEC SC = 12021. Data-limites: 1948-1975, Arquivo Nacional de Timor-Leste.

${ }^{7}$ Exame de admissão aos Institutos Industriais Geografia e História - Documento: Administração Portuguesa em Timor-Leste, Série: Instituição Pública e Educação e Escola, Caixa 2 - Modelo III-B TL AN TP AC IPEE OF = 1-20, Data-limites: 1943-1974, Arquivo Nacional de Timor-Leste.
} 
Ensino Secundário Técnico. Nessa prova, fica evidente a descontextualização da Geografia em relação à realidade timorense, pois pode-se observar que não existe a menção de uma geografia de Timor-Leste. Na questão sobre clima, é feita uma pergunta sobre o clima de monções, mas sem o relacionar com a posição geográfica da ilha de Timor (sudeste asiático) que está diretamente sobre a influência desse clima e, por exemplo, a sua importância no cultivo de arroz existente na então colônia.

Nota-se, assim, o projeto de Portugal em construir um discurso de Província Ultramar, que de certa forma isolou Timor-Leste dos outros países da Ásia. Timor Português não era ocidental geográfica e culturalmente, mas também não se criou uma ideia de pertencimento enquanto um país asiático, tornando-se uma cultura muito particular. As questões temporais e espaciais vivenciadas pelos timorenses não eram mencionadas na sala de aula; a título de exemplo, não se encontra qualquer menção de ensinamentos sobre a riqueza da variedade linguística e cultural do povo maubere ${ }^{8}$ ou sobre as emaranhadas relações históricas e geopolíticas com as nações asiáticas vizinhas.

Nesse período, a ilha de Timor só tinha importância quando estava relacionada com acontecimentos enquanto colônia da Holanda ou de Portugal, objetivando o alargamento do poder das metrópoles e o mapeamento geográfico das colônias, assim como as revoltas que apareciam contra as expansões da metrópole, ou seja, os timorenses só apareciam na Geografia escolar quando tinham contato com seus colonizadores. Sousa (2013, p. 31), em análise sobre a representação dos timorenses nos manuais portugueses de Geografia do Estado Novo vivenciado na então colônia Timor-Leste (1933-1974), nos releva que

Em relação à representação de Timor e dos timorenses nos manuais escolares do Estado Novo observa-se que a sua presença e descrição evoluem no tempo, passando de uma descrição passageira e simplista, baseada em pressupostos raciais, para uma abordagem emotiva e afetiva, conotada com lealdade e amor a Portugal, (enquanto oculta, por exemplo, as revoltas de Manufahi em 1912 e Viqueque em 1959). A representação de "Timor português" é, sobretudo, a prova

8 Termo utilizado pelos timorenses para designar a população nativa (COSTA, 2000). 
distante (espacial) da expansão colonizadora portuguesa, e estes atos de "amor" e "lealdade" dos seus membros reforçam a justificação da missão civilizadora, a posse e integração colonial, ultramarina, "pluri", de espaços e gentes.

Com isso, nota-se o silenciamento de contextos importantes de resistência frente à colonização portuguesa; em contrapartida, enfatiza-se uma narrativa romantizada sobre a relação entre o colonizador e o colonizado, expressando, assim, o perigo de uma história e uma geografia apresentadas unicamente pela visão dos colonizadores, a qual impossibilita a construção de diferentes visões sobre as complexidades vivenciadas nos fatos históricos e sobre a formação socioterritorial desse país. De acordo com Fanon (1968, p. 77), "o bem-estar e o progresso da Europa foram construídos com o suor e o cadáver dos negros, árabes, índios e amarelos, convém que não nos esqueçamos disto". Assim, a reprodução do pensamento ocidental pelos timorenses culminou na "cultura do silêncio".

Raffestin (2007, p. 11) diz que "o homem habita o território, mas ele não habita no sentido de um animal porque ele existe através da razão, da memória e da imaginação que ele tem do seu território". Assim, desde a antiguidade, a apropriação do saber geográfico sobre um determinado espaço é concebida como um saber estratégico de diferentes grupos (políticos e econômicos), de modo que sejam utilizados como uma das formas para a manutenção desses grupos no poder, mantendo-se assim, o status quo do sistema colonial, dado que a formação do território colonial se deu por uma mobilidade dos sujeitos no espaço e, desse modo, percebe-se que nunca foi de interesse da metrópole desenvolver e compartilhar tais saberes com o povo timorense.

Adiante, já no período da ocupação Indonésia (1975-1999), é essa nação que passa a escrever sobre a geografia de Timor-Leste. De acordo com Fonseca (2010, p. 18), durante este período ocorreu uma descaracterização paulatina da cultura lusotimorense, visto que, com a proibição do ensino da língua portuguesa em todos os níveis de ensino, o bahasa indonesio passou a ocupar esse lugar, e, com isso, passou a ser ensinada "toda a história e a cultura indonésia, sendo Timor-Leste (Timor Timur) visto sob o ponto de vista do ocupante como sua vigésima sétima província”. Esse regime de ocupação foi fundado a partir de um 
genocídio em Timor-Leste, em que cerca de duzentos mil timorenses foram mortos, ou um quarto da população total, havendo também uma forte repressão generalizada por todos os lados desse território para legitimar sua política de integração e com a intenção de promover a "indonesação" do território recéminvadido.

Segundo Ma'averu (2018), um dos argumentos históricos utilizados pelo regime indonésio para efetivar a anexação territorial era de que a ilha de Timor tinha uma linha de conexão com o Império Majapahit ${ }^{9}$, o que, anacronicamente, colocava a República Indonésia moderna como herdeira da fronteira geográfica desse império. Ainda segundo o autor, a integração de Timor-Leste como "território indonésio" foi discursivamente anunciada nas aulas de geografia como um "retorno à Mãe Pátria".

Ma'averu (2018), também aborda, que o regime ditatorial indonésio para se manter no poder, agiu sempre de maneira hegemônica e coerciva, controlando a produção de conhecimento, removendo do currículo qualquer perspectiva sobre os direitos humanos e excluindo a história da luta dos timorenses pela sua independência. Para compreender melhor esse contexto, um de nossos interlocutores, o então diretor da Unidade de Produção e Disseminação do Conhecimento da Universidade Nacional Timor Lorosa'e (UPDC/UNTL), relatou que,

Durante a ocupação Indonésia, no currículo, colocava-se TimorLeste como a $27^{\circ}$ província da Indonésia. E nos conteúdos também modificou [em relação ao currículo anterior, de origem portuguesa], porque não se designava diretamente "o rio de Timor" ou "topografia de Timor", mas o ligava um pouco à Indonésia, e só depois que entra no concreto de Timor. Faz parte da colonização. Sendo assim, o currículo em si estava bem organizado, porque a Indonésia já havia adquirido a independência há uns trinta anos. Nós não podemos afastar isso: era um currículo bem elaborado, só que afastando um pouco o conteúdo identitário. Por exemplo, falava-se de

\footnotetext{
9 O Império de Majapahit foi um reino indianizado baseado na parte oriental da ilha de Java, que existiu entre 1293 e 1527. Seu maior governante foi Hayam Wuruk, cujo reinado durou de 1350 a 1389, marcando o auge do império, quando dominou os reinos do sudoeste marítimo da Ásia (atualmente os territórios da Indonésia, Malásia e Filipinas). Esse foi o último dos reinos hindus do Arquipélago Malaio e é considerado um dos maiores estados na história da Indonésia, com uma influência que se estendia a estados em Sumatra, na península da Malásia, Bornéu e Indonésia oriental, embora a sua extensão seja um tema controverso (MARTINHO, 1943).
} 
Geografia Humana, mas humana de quem? Humana timorense ou humana indonésia? É aí que ocorre uma "indonesação dos timorenses" (Entrevista realizada em Díli - novembro de 2017).

Com o fim da ocupação indonésia, após um cenário de completa destruição do sistema educacional de Timor-Leste, avançando para o contexto de restauração da independência timorense, entre os anos de 1999 a 2002 momento em que esse território ficou sob a administração da UNTAET - é possível dizer que nesse período, apesar do apoio internacional, a realidade do sistema educacional timorense ainda era precária no que diz respeito à infraestrutura e aos equipamentos (edifícios, bibliotecas, recursos humanos e materiais escolares).

Segundo Cardoso (2012), nas escolas timorenses os professores ainda utilizavam os manuais de herança indonésia ou dependiam de outros materiais aos quais conseguiam ter acesso para ensinar. Outro interlocutor, exembaixador de Timor-Leste no Brasil, explicou em entrevista sobre as dificuldades desse período.

Eu fui diretor geral da educação, logo após a independência e vimos que realmente faltava muita gente [profissionais da educação], sobretudo no nível secundário. Havia poucos professores, porque muitos deles eram indonésios e foram embora [...]. Logo após a independência nós precisávamos de professores, no meu termo, para entreter os alunos! Não digo para ensinar, mas para entreter! Porque veio a independência e as crianças pediam professores, mas as escolas não estavam em condições [de funcionar]. Muitas escolas foram queimadas, entre outras coisas, e desapareceram quase todos os documentos. Então, como não havia professores, recrutava os universitários. Aqueles que tinham o terceiro, quarto ou quinto ano, recrutávamos. [Dizia]: "Vocês vão ensinar lá para entreter as crianças e acabou!", Para nós, se era para fazer asneiras lá na rua, então era melhor que fizessem alguma coisa [na escola]. Era uma situação abertamente de emergência naquela altura. Aos poucos fomos abrindo as escolas. $O$ que vocês veem hoje, não foi [existia] há 10 ou 15 anos atrás, né? As escolas estavam todas queimadas, não havia gente, e aquela era uma situação mesmo caótica, uma situação caótica! Hoje a situação melhorou. Hoje, nós estamos a pensar o problema que nós temos hoje, que é mais de qualidade (Entrevista realizada em Díli - outubro de 2017 - grifo nosso). 
Após ser reconhecido como Estado soberano em 2002, no âmbito das políticas de formação de Estado, o país oficializou a língua portuguesa e a entrada de Timor-Leste na Comunidade dos Países de Língua Portuguesa (CPLP) e, assim, iniciou-se a entrada das cooperações na área educacional desse país com o objetivo de focalizar no ensino em língua portuguesa.

O governo timorense, em parceria com a Cooperação Portuguesa, buscou, a partir de 2005, a reestruturação do seu sistema educacional, e gradualmente foi elaborando e implementando as reformas curriculares em todos os níveis de ensino, assim como a distribuição de novos materiais didáticos. Já a reforma curricular

\begin{abstract}
iniciou-se no ano de 2010, inserida numa reforma mais ampla do sistema educativo, baseada na identidade, na cultura, na moral e na religião do país. A mudança do sistema educativo foi lançada pelo governo timorense, através do Ministério da Educação, e teve reflexos significativos ao nível da organização curricular, dos programas disciplinares, dos calendários escolares, do início do ano letivo, da avaliação curricular e da ação dos professores nas escolas básicas e secundárias. As principais dificuldades encontradas na implementação da reforma educativa [e curricular] em curso surgem associadas às mudanças de áreas e/ou disciplinas, em particular na disciplina de Ciências Exatas e na disciplina de História e Geografia (CARDOSO, 2012, p. 15).
\end{abstract}

Frente à reforma curricular no pós-independência, é importante problematizar a forma como a Geografia está presente nos documentos curriculares, e consequentemente nos materiais didáticos desse país. No âmbito da atual Reestruturação Curricular de Timor-Leste, consideramos os livros didáticos ${ }^{10}$ (Manuais dos Alunos e Guias dos Professores) como parte da materialidade discursiva do atual currículo e, com isso, a necessidade de atenção ao que seus discursos refletem, pois a produção desses materiais é feita por estrangeiros, e eles nem sempre representam as perspectivas e as epistemes timorenses. A legitimação desse cenário pode ser verificada em uma

\footnotetext{
10 "Os conteúdos dos livros didáticos podem ser compreendidos como parte daquilo que está autorizado, no plano das práticas discursivas, a pertencer ao discurso do conhecimento escolar em Geografia" (VILELA, 2014, p. 56).
} 
entrevista realizada com o então diretor geral do departamento de currículo em Timor-Leste. Segundo o diretor, a reestruturação do currículo desse país deve seguir um padrão mundial e um modelo curricular único e igual:

[...] Todo mundo aprende ciência. O que você [o aluno] aprende aqui [em Timor-Leste], vai obter alguma competência a mesma [em relação] com outros [currículo] que estão lá fora. Por exemplo: no Brasil aprende-se Matemática, mas o conteúdo de matemática que você [o aluno] aprende lá, em Timor [o aluno] tem que aprender também, e isto que é o padrão internacional, porque currículo e a ciência é para todo mundo [...] Temos que ser igual uns aos outros. Então, o currículo em si tem que ser assim, você aprende matemática lá, por exemplo equação lá em Brasil, aqui no Timor tem que aprender também equação, [...] por que depois os estudantes vão ter bolsas de estudo para fora [...] e nós não vamos ficar mais atrasados com os outros, então, aí currículo tem que ser igual (Entrevista realizada em Díli agosto de 2017).

Por essa razão, Paulino (2018, p. 90) nos alerta de que a elaboração do atual currículo nacional ainda segue padrões internacionais e que

\begin{abstract}
A transferência do saber no ensino de história e de geografia de Timor-Leste assenta-se na realidade do país e na própria alma timorense, pois não somos europeus, nem africanos e muito menos americanos. Por isso mesmo é que precisamos, urgentemente, de discutir com clareza aspetos de "timorização timorense" no ensino da história e geografia humana e em especial num quadro da consolidação da identidade nacional e cultural.
\end{abstract}

Nesse mesmo sentido, Cardoso (2012, p. 42) discute que no atual processo de reforma curricular ainda persiste um problema - as organizações responsáveis pela produção desses materiais não consideram as disparidades econômicas e sociais entre as diferentes regiões do país, "na verdade a adoção de uma certa concessão de sociedade e de educação, destinada a aplicar a todos os países, nem sempre se adequa a todos os contextos, tal como acontece com algumas regiões de Timor-Leste".

Diante disso, evidencia-se ainda uma certa descontextualização dos conhecimentos e conteúdos curriculares com a realidade timorense. Após 
apresentar esses fragmentos, pode-se dizer que ao longo da história da disciplina de Geografia de Timor-Leste encontramos sistemas educacionais voltados a atender à manutenção da colonização e da ocupação territorial, apresentando conhecimentos descontextualizados, conteúdos curriculares estáticos e descritivos. Ainda hoje, muitas vezes, o que se ensina nas escolas parece não estar vinculado à vida dos sujeitos, apresentando-se somente como uma lista de lugares, personagens, nomes, datas e formas que precisam ser decorados e devolvidos para a realização de exames semestrais ou anuais.

\section{INDÍCIOS DE COLONIALIDADE NO MANUAL DO ALUNO DO 10 DO ENSINO SECUNDÁRIO GERAL: (RE)PENSANDO A TIMORIZAÇÃO DA GEOGRAFIA ESCOLAR DE TIMOR-LESTE}

O atual currículo do Ensino Secundário Geral (ESG) é resultado do Projeto de Reestruturação Curricular do Ensino Secundário Geral ${ }^{11}$ em Timor-Leste, desenvolvido entre janeiro de 2010 a março de 2013. O Plano Curricular do ESG foi aprovado em 2011, enquanto que os novos programas começaram a ser implementados em fases e com sucessivos atrasos. Por exemplo, os materiais didáticos de apoio do $10^{\circ}$ ano foram distribuídos já em pleno andamento do ano letivo de 2012 , enquanto que o $11^{\circ}$ e $12^{\circ}$ anos foram distribuídos praticamente em simultâneo no ano 2014.

Segundo Vilela (2013), as obras didáticas demonstram o cenário de disputas pela significação curricular, de modo que, enquanto registros documentais, materializam sentidos de conhecimento escolar em Geografia. Dessa forma, direcionar um olhar para os livros didáticos pode ser um movimento favorável para a identificação de concepções de geografia associadas a específicos movimentos autorais em meio à luta pela significação curricular na disciplina. Ainda segundo a autora, se de um lado, os conteúdos presentes nos livros didáticos não representam a totalidade do que acontece na escola, de outro, eles são evidências daquilo que é afirmado como "o que pode ser ensinado" em uma certa disciplina escolar, em um certo tempo, sendo que essa

\footnotetext{
11 Para mais informações sobre o projeto ler Barbosa (2018), Martins e Ferreira (2013) e Ramos e Teles (2012).
} 
abordagem se desenha quando se assume o conhecimento escolar e as disciplinas escolares como disputas que ocorrem no nível das práticas discursivas.

Nessa direção, Silva (2011, p. 181) destaca que "[...] toda vez que um livro é produzido, ele carrega consigo regras - implícitas ou explícitas - que buscam guiar os olhos dos leitores, o que pode ser definido como uma leitura autorizada". Nos manuais dos alunos de Geografia de Timor Leste, cada unidade é introduzida por um pequeno texto que contextualiza a temática no território timorense. Para cada subtema são apresentadas questões orientadoras, os conceitos-chave que os alunos devem aprender e as metas de aprendizagem que os professores devem atingir. As questões orientadoras em cada um dos subtemas são desdobradas ao longo do texto em questões mais simples.

No final de cada subtema é feita uma síntese das principais ideias que emergiram da temática em estudo (ideias-chave). Por último, são deixadas questões em aberto (exercício de aplicação). Na parte final dos manuais dos alunos é apresentado um glossário com o significado dos principais conceitoschave necessários à compreensão dos conteúdos relativos às temáticas abordadas no respectivo ano de escolaridade.

Neste trabalho, escolhemos analisar o conteúdo programático do $10^{\circ}$ ano. Ressaltamos que não foi empreendido um olhar analítico buscando enumerar conteúdos, mas privilegiou-se as temáticas que estabelecem estreitas relações com questões referentes à subalternização dos sujeitos timorenses frente aos europeus produtores desses recursos didáticos.

No Manual do Aluno de Geografia do $10^{\circ}$ ano do ESG, analisamos a Unidade Temática 1 - "Timor-Leste, na Ásia e no Mundo", mais especificamente, - Subtema 1 que aborda a temática "Localização geográfica de Timor-Leste na Ásia e no Mundo". Essa unidade é composta por três páginas (11-13), subdivididas em duas partes: 1.1 Localização geográfica de Timor-Leste; 1.2 Relações de Timor-Leste com o mundo.

Ao analisar esse subtema, identificamos uma única imagem (figura 1) que aborda a temática sobre a localização geográfica de Timor-Leste em relação a sua posição no Continente Asiático e no mundo. 


\section{Figura 1. Imagem utilizada no Manual do Aluno do $10^{\circ}$ ano para abordar a localização geográfica de Timor-Leste.}

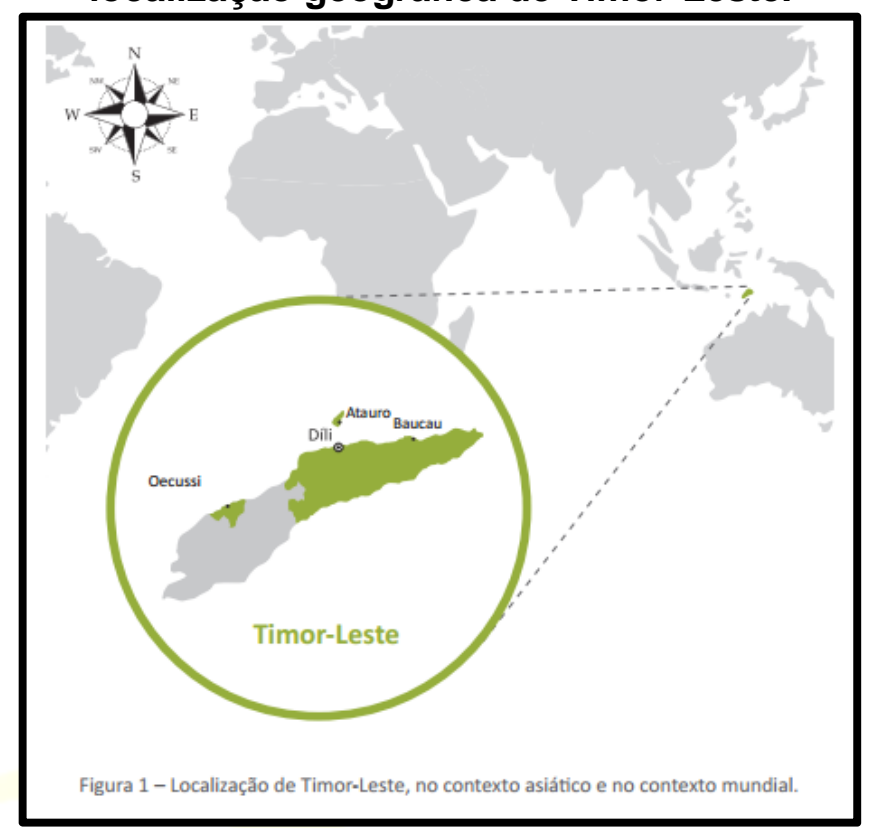

Fonte: RDTL, 2012, p. 11.

Essa imagem, além de não fazer menção a qualquer escala de utilização, ainda traz em destaque o Continente Europeu no centro desse "contexto mundial", de modo que mantem a localização da antiga metrópole portuguesa no centro do mundo, alimentando o eurocentrismo e manifestando as marcas da colonialidade. Saliento ainda que, nessa representação, o Continente Americano está recortado, além de não haver destaque na legenda e em nenhum outro momento do texto sobre as distorções inerentes às diferentes projeções cartográficas que poderiam ser utilizadas no ensino de Geografia.

Em entrevistas realizadas com professores de Geografia do ESG que lecionam em escolas da capital, Díli, um dos interlocutores relatou que apenas essa imagem, presente no manual, é apresentada em sala de aula:

Tem muitas dificuldades [problemas] o Manual. Tem alguns conteúdos com poucas imagens e fica difícil trabalhar com os alunos. Eles têm dificuldade com a língua [portuguesa], então, a imagem é importante. Na minha escola não tem outros mapas para trabalhar com os alunos, só os mapas que estão no Manual (Entrevista realizada na Escola Professor Paulo VI em Díli setembro de 2017). 
É fundamental nas aulas de Geografia a problematização sobre a escolha das projeções cartográficas e suas representações, pois essas trazem consigo distorções e representam escolhas que podem "aumentar" ou "reduzir" o tamanho das áreas e que, por estarem centradas em um determinado ponto de vista, criam a ideia de países localizados no "centro" do mundo e países localizados nas "periferias". Para Harley (2009, p. 11),

\begin{abstract}
A concepção gráfica que determina o lugar central ou a projeção, fixando o modo de transformação em relação ao globo terrestre, é um elemento que pode amplificar o impacto político de uma imagem, mesmo quando alguma distorção não é buscada conscientemente (...) Portanto, os mapas tendem a focalizar a atenção do observador sobre o centro e a promover assim o desenvolvimento de visões de mundo exclusivas, voltadas para o interior com um centro cultural povoado unicamente de verdadeiros crentes..."
\end{abstract}

Nessa mesma direção, para Tonini (2006, p. 61) "isso mostra a construção de uma rede de significados que, além de produzir seus efeitos de verdade, constrói um saber que classifica, nomeia, regula a população", evidenciando a manutenção de uma colonialidade, ou seja, essa representação ainda mostra as amarras dos efeitos da dominação colonial, e é possibilitada pelo fato de os portugueses, no âmbito da Reestruturação Curricular do Ensino Secundário, manterem uma hegemonização discursiva na construção desses manuais.

Apoiados no trabalho de Walsh (2009), consideramos que esse movimento de colonialidade na elaboração e implementação dos Manuais dos Alunos de Geografia, se caracterizando como uma colonialidade do saber, além de desencadear uma série de dificuldades e desafios no funcionamento e na consolidação de um sistema educacional timorense, aponta para a imposição de uma perspectiva hegemônica do conhecimento, ou seja, o conhecimento eurocêntrico e ocidental é reconhecido como universal em detrimento de saberes considerados "outros".

Continuando a análise do Manual do Aluno de Geografia do 10 do ESG, a discussão sobre as relações que Timor-Leste estabelece com outras partes do mundo, apresenta apenas do seguinte enunciado: 
As relações que Timor-Leste tem estabelecido com o exterior passam pela sua participação em organizações internacionais de grande importância, como é o caso da Organização das Nações Unidas (ONU), da Associação das Nações do Sudeste Asiático (ASEAN) e da Comunidade de Países de Língua Portuguesa (CPLP) (RDTL, 2012, p. 12 - grifo nosso).

Após esse enunciado, o manual enfatiza apenas as relações de TimorLeste com a CPLP. Esse destaque atribuído à CPLP, determinando que os professores timorenses de Geografia ensinem as metas e a importância da CPLP para o país, pode se constituir como um elemento que justifica a presença e a relevância dos portugueses em território timorense.

Além da CPLP, torna-se importante que o Manual do Aluno de Geografia do $10^{\circ}$ ano do ESG aprofunde a participação de Timor-leste em outras organizações internacionais, como por exemplo, a Associação das Nações do Sudeste Asiático (ASEAN). Haesbaert e Porto-Gonçalves (2006) discorrem que, nos últimos anos, tem-se desenhado uma nova e complexa geografia do mundo, pois enquanto o Word Trade Center desabava, as torres gêmeas de Kuala Lumpur e o projeto de torres e edifícios maiores do mundo, na China reafirmavam o novo poder do Oriente. Sobre esse aspecto, outro professor de Geografia, nos disse em entrevista que:

\footnotetext{
Estamos em constante discussão com ASEAN, alguns países querem a entrada de Timor, outros não. Essa é uma geopolítica muito importante para o país, estamos do lado dos Tigres Asiáticos, países fortes e importantes, grandes potências também. É importante Timor ser reconhecido (Entrevista realizada na Escola Professor Paulo VI em Díli - setembro de 2017).
}

A partir desse enunciado, notamos o quanto seria importante retirar da Europa sua posição de "centro" do mundo, rompendo com a produção de um recurso didático ocidental e distante de Timor-Leste. Como foi aludido, isso é reflexo do manual didático ser produzido sob o prisma do "estrangeiro dominante", uma vez que destacou-se, mesmo que subjetivamente, apenas as ações portuguesas, sem se enfatizar as discussões atuais que estão ocorrendo num país localizado no sudeste asiático. 
Nessa direção, pensando no papel ativo e decolonial da Geografia escolar, podemos dizer que os enunciados presentes no Manual do Aluno aqui analisado, através da internalização de sentidos discursivos produzidos pela Cooperação Portuguesa e inseridos nos conteúdos de tradição geográfica, agem na significação do imaginário de território e de nação nos estudantes timorenses. Afirmamos, mais uma vez, que um material didático não pode ser considerado somente um "depósito" de conteúdos, "[...] um lugar em que os autores registram os conhecimentos geográficos, mas também, [...], como um lugar de produção de significados, como um artefato cultural no qual as verdades são fabricadas e postas em circulação" (TONINI, 2006, p. 32).

Reconhecendo as relações de poder e respeitando as diferenças históricas e epistemológicas, buscamos a possibilidade de diálogos entre os discursos ocidentalizados e eurocêntricos (presentes nos materiais analisados) e os conhecimentos e saberes timorenses, dando ênfase à possível insurgência da timorização da Geografa escolar. Uma vez que, segundo o diretor da UPDC/UNTL:

O currículo está aí! E demorou para sair, e ainda hoje não está em todos as escolas do país de forma igual. Desde 2012, os professores estão tentando trabalhar com esse material, tendo dificuldades com a língua [portuguesa] e com os conteúdos. O governo também gastou muito dinheiro para implementar esse currículo, então não podemos simplesmente jogar fora. Precisamos avaliar os erros, reformular e timorizar os conteúdos (Entrevista realizada em novembro de 2017).

Sobre a timorização, com base em Costa (2016), podemos dizer que esse processo começou logo após a Revolução dos Cravos, que ocorreu em Portugal em 1974, quando se estabeleceu em Timor-Leste o Grupo Coordenador para a Reformulação do Ensino em Timor (GCRET). Um dos principais objetivos desse grupo era discutir os programas de História e Geografia e a descontextualização dos manuais dessas disciplinas frente à realidade timorense. Em 1975, a proposta do GCRET para a reformulação do ensino passou a encontrar em Timor-Leste a oposição de alguns professores tradicionalistas e parte dos membros da Igreja Católica, pois esses viam tais mudanças educacionais como 
uma perigosa influência comunista, reagindo, assim, contra essa reformulação e contra todas as ações de descolonização do ensino timorense. A invasão Indonésia que ocorreu em dezembro desse mesmo ano impediu por completo qualquer efetivação da proposta de timorização.

Porém, com a restauração da independência em 2002, a ideia da timorização voltou a ganhar forma como discurso interpretativo, sendo redefinido com uma mudança significativa para as práticas sociais timorenses. A então, vice-ministra da Educação de Timor-Leste, Exa. Sra. Dulce de Jesus Soares, salienta que desde 1975 concluiu ser necessário timorizar o ensino, os seus objetivos, métodos e programas (RDTL, 2017). Segundo a Vice-ministra, "já tinha sido declarado [...] ser essencial promover um ensino prático relacionado com a realidade timorense, respondendo as necessidades de Timor-Leste, ligando a escola à vida das populações que esta se insere" (RDTL, 2017, p. 143).

Em relação à realidade da educação em Timor-Leste, Silva (2016) critica a imposição da ciência e tecnologia estrangeira, que significa a imposição da epistemologia eurocêntrica e suas línguas imperiais (inglês, francês, português, alemão, espanhol e italiano). Segundo esse autor, a herança colonial foi profundamente internalizada no sistema educacional timorense, a partir da imposição de uma alfabetização pautada na cultura grega e romana e, consequentemente, na subalternização dos conhecimentos nativos. Dessa forma, a educação colonial foi orientada para o domínio do conhecimento dos colonialistas. Ainda para Silva (2016), aprendemos a matemática, as ciências naturais, a filosofia e as ciências sociais desenvolvidas na Europa, ou seja, o sistema de educação reproduz a ciência universal e um modo de vida eurocêntrico. No caminho contrário a essa herança colonial, a "educação timoriana tem outro objetivo: resgatar a educação do período da resistência e o conhecimento baseado nas cosmologias das terras de Timor" (Ibidem, p. 159).

Nessa perspectiva, de acordo com Paulino (2017), é possível pensar uma educação a partir da cultura timorense, valorizando as suas narrativas de origem, que foram herdadas dos seus antepassados na forma de lendas, contos, fábulas e mitos. Nas cerimônias rituais, tais como os ritos agrícolas, são invocadas personagens das narrativas de origem (divindades supremas e divindades 
intermediárias, como espíritos da natureza e espíritos dos antepassados). Para esse autor, essas narrativas estão associadas a entidades que as conservam oralmente, como autoridades rituais (lia na'in) que transmitem a mensagem dos ancestrais nos lugares sagrados, como na casa sagrada (uma lulik) e no altar sagrado (bosok).

Concordando com esses autores (SILVA, 2016; PAULINO, 2017) defendemos assim, a timorização da Geografia escolar desse país, que se configuraria como um movimento cujos contornos se revelam nas próprias formas de enunciação da geografia nacional, ou seja, seria caracterizada como novas formas de representação na linguagem geográfica. Nesse caminho, questionamos: se o lulik, se a cosmologia com terra, se as tradições orais que são tão presentes na identidade timorense, porque elas não podem estar presentes também no currículo de Geografia? Portanto, consideramos necessária a timorização como uma forma de expressão timorense nos currículos.

Sobre possíveis caminhos para a timorização da Geografia escolar, em entrevista com um funcionário do Ministério da Educação que atua no Apoio Técnico da disciplina de História e Geografia (3ำ ciclo), ele relata como estão ocorrendo as primeiras reformulações dos currículos:

Para os estudantes do $1^{\circ}$ e $2^{\circ}$ ciclos estamos finalizando um Atlas,. Tem uma equipe para a reformulação, porque nós não temos cartógrafos, então, nós convidamos um colega (timorense) graduado em Geografia. Ele trabalhava em agência que elaborava mapas e ele que ajudou a elaborar o Atlas, mas a ideia para desenvolver foi pensada pela equipe de reformulação. Na geografia ainda estamos tentando reformular numa perspectiva timorense, tenho utilizado também autores australianos, indonésios e franceses e comparando, e reinterpretando conceitos. A Geografia hoje nos currículos é muito descritiva, só descreve as paisagens de Timor. Precisamos desenvolver o pensamento crítico. Acredito que com a reformulação, esse currículo é o mais ligado com o processo de timorização, tem uma equipe internacional que trabalha também, mas na escrita tem uma troca de conhecimento, depois processo de discussão e também nós conversamos com os professores timorenses, e também com pessoas chaves, como Ramos Horta, Xanana Gusmão, os acadêmicos Armindo Maia, Antero Benedito, Roque Rodrigues, Domingos de Sousa. 
Diante do exposto, descontruindo o imaginário colonial de que existe um outro a ser descoberto e descrito, nota-se que os timorenses são sujeitos ativos frente aos currículos, eles estão resistindo, discutindo e reformulando os materiais que hoje circulam nas escolas em âmbito nacional. Todos esses movimentos, compostos principalmente por timorenses, buscam outras formas de (re)existir socialmente, lutando por uma igualdade mais ampla dos papéis sociais, sem esquecer os aspectos tradicionais e sagrados da sua cultura.

\section{BREVES CONSIDERAÇÕES}

Identificamos que a produção dos materiais didáticos em Timor-Leste foi feita por estrangeiros, de modo que nem sempre representam as perspectivas e as epistemes timorenses, isto é, ainda não contemplam a timorização da Geografia escolar.

Partindo esse contexto, consideramos importante buscar caminhos decoloniais, ou melhor, uma timorização que permita que os professores timorenses de Geografia sejam protagonistas nos processos de elaboração, avaliação e implementação curricular e que, no ensino de Geografia, esses docentes autônomos e emancipados possam contemplar e problematizar os contextos em que vivem, dando ênfase aos seus aspectos histórico, social e cultural.

Vários interlocutores timorenses que possuem ligação com a educação, destacaram a importância de reformular o atual currículo de Geografia no país seguindo uma perspectiva timorense, ou seja, apresentar aspectos e características timorenses. Nesse caminho, questionamos: por que o lulik, e sua cosmologia com terra e as tradições orais, tão presentes na identidade timorense, não podem estar presentes também no currículo de Geografia? Portanto, ressaltamos a necessária timorização da Geografia escolar como uma forma de expressão timorense nos currículos.

Em termo de considerações, enfatizamos que este texto, antes de ser compreendido como algo concluído e terminado, pode ser representadopor (in)conclusões e reflexões dentro de um movimento de pensar e fazer currículo, 
que buscou compreender, sob a ótica da Teoria do Discurso, dos estudos póscoloniais e decoloniais, o histórico da Geografia escolar timorense voltada para atender à manutenção da colonização portuguesa e da ocupação territorial indonésia e, que atualmente, está ligada a uma ótica geográfica estrangeira.

\section{REFERÊNCIAS}

BARBOSA, Alessandro Tomaz. (De)colonialidade no currículo de Biologia do ensino secundário geral em Timor-Leste. Tese (Doutorado em Educação Científica e Tecnológica) - Universidade Federal de Santa Catarina, 2018.

BARBOSA, Alessandro Tomaz; DINIZ, Vanessa Lessio; PAULINO, Vicente. Currículo, cultura e educação em Timor-Leste: conflitos e resistências entre 0 local e o global. In: BARBOSA, Alessandro Tomaz; DINIZ, Vanessa Lessio; PAULINO, Vicente (Org,). Currículo e educação: Timor-Leste em destaque. Díli: Unidade de Produção e Disseminação do Conhecimento Programa de PósGraduação e Pesquisa da UNTL, 2020.

BURITY, Joanildo Albuquerque. Discurso, política e sujeito na teoria da hegemonia de Ernesto Laclau. In: MENDONÇA, Daniel de; RODRIGUES, Leo Peixoto (Orgs.). Pós-estruturalismo e teoria do discurso: em torno de Ernesto Laclau. Porto Alegre: EdiPUCRS, 2014.

CABRAL, Amílcar. Unity and struggle: speeches and writings of Amílcar Cabral, texts selected by the PAIGC. Nova York: Monthly Review Press, 1979.

CARDOSO, Maria Lourdes. Reforma curricular em Timor-Leste: estudo exploratório sobre a disciplina de ciências físico-naturais no ensino básico. Dissertação (Mestrado em Ciências da Educação) - Universidade do Minho, Minho, 2012.

COSTA, Daniel De Lucca Reis. A timorização do passado: nação, imaginação e produção da história em Timor-Leste. Tese (Doutorado em Ciências Sociais) Universidade Estadual de Campinas, Campinas, 2016.

COSTA, Hugo Heleno Camilo; PEREIRA, Talita Vidal. Sentidos de Interdisciplinaridade articulados nas políticas de currículo: o caso das disciplinas Ciências Naturais e Geografia. Cadernos de Educação. Pelotas, v. 44, p. 293318, 2013.

COSTA, Luís. Dicionário de Tétum-Português. Lisboa: Colibri; Universidade de Letras de Lisboa, 2000. 
DALE, Roger. Globalisation: a new world for comparative education? In: SCHREIWER, J. (Org.). Discourse formation in comparative education. Berlim: Peter Lang, 1998.

DINIZ, Vanessa Lessio; MA'AVERU, Rogério Sávio. História e Geografia de Timor-Leste: (re)conhecer o passado dessas disciplinas para timorizar o presente. In: ARAÚJO, Irta Sequeira Baris de (Org.) Leituras atuais sobre língua, ensino e didática em Timor-Leste. Dili: Unidade de Produção e Disseminação do Conhecimento Programa de Pós-Graduação e Pesquisa da UNTL, 2019.

DINIZ, Vanessa Lessio. Currículo e sentidos de geografia em Timor-Leste: disputas na significação da identidade nacional timorense. Tese (Doutorado em Geografia) - Universidade Estadual de Campinas, Campinas, 2019.

FANON, Frantz. Os condenados da Terra. Rio de Janeiro: Editora Civilização Brasileira, 1968.

FONSECA, Sabina da. Análise dos Manuais de Língua Portuguesa utilizados no Ensino Primário em Timor-Leste. Dissertação (Mestrado em Ensino de Português) - Universidade Nova de Lisboa, Lisboa, 2010.

GOODSON, Ivor. Currículo: teoria e história. Petrópolis: Vozes, 1995.

HAESBART, Rogério. Território e descolonialidade: sobre o giro (multi) territorial/de(s)colonial na América Latina / Rogério Haesbaert. Buenos Aires: CLACSO, 2021.

HAESBAERT, Rogério; PORTO-GONÇALVES, Carlo Walter. A nova desordem mundial. São Paulo: Editora UNESP, 2006.

HALL, Stuart. Cultura e representação. Trad. Daniel Miranda e William Oliveira. Rio de Janeiro: Ed. PUC-Rio, Apicuri, 2016.

HARLEY, John Brian. Mapas, saber e poder. Confins, n. 5, p.1-24, 2009.

LACLAU, Ernesto. Misticismo, retórica y política. Buenos Aires. Fondo de Cultura Económica, 2002.

LACLAU, Ernesto. Emancipação e diferença. Rio de Janeiro: EdUERJ, 2011.

LOPES, Alice Casimiro. Políticas de Currículo: questões teórico-metodológicas. In: LOPES, Alice Casimiro; DIAS, Rosanne Evangelista; ABREU, Rozana Gomes de (Orgs.). Discursos nas políticas de currículo. Rio de Janeiro: Quartet, 2011.

LOPES, Alice Casimiro. Teorias pós-críticas, política e currículo. Revista Educação, Sociedade \& Culturas, no 39, p. 7-23, 2013. 
LOPES, Alice Casimiro; MACEDO, Elizabeth. Teorias de Currículo. São Paulo: Cortez, 2011.

MA'AVERU, Rogério Sávio. A “Timorização” da História: pesquisa histórica e produção de manuais didáticos. Apresentação no Seminário do Conselho Latino-Americano de Ciências Sociais (CLACSO). Centro de Estudos Sociais (CES) da Universidade de Coimbra,2018.Disponívelem:<https://www.youtube.com/watch?v=lkvfQas_qdA \&feature=youtu.be $>$. Acesso em: 18 de agosto de 2018.

MACEDO, Elizabeth. Currículo como espaço-tempo de fronteira cultural. Revista Brasileira de Educação. São Paulo, n. 32, v. 11, maio-ago. ANPED, 2006.

MALDONADO-TORRES, Nelson. Sobre la colonialidad del ser: contribuciones al desarrollo de um concepto. In: CASTRO-GÓMEZ, Santiago; GROSFOGUEL, Ramón. (Orgs.). El giro decolonial: Reflexiones para una diversidad epistémica más allá del capitalismo global. Bogotá, 2007.

MARTINHO, José Simões. Timor: quatro séculos de colonização portuguesa. [S.I.]: Livraria Progredior, 1943.

MARTINS, Isabel; FERREIRA, Ângelo. A Reestruturação Curricular do Ensino Secundário Geral em Timor Leste: um caso de cooperação da Universidade de Aveiro no domínio da educação. In: Morais, Carlos; Coimbra, Rosa Lídia (Orgs.). 3. Congresso Internacional "Pelos mares da língua portuguesa". Universidade de Aveiro, 2013.

MIGNOLO, Walter. Histórias locais/Projetos globais. Belo Horizonte: Editora da UFMG, 2003.

MUNSBERG, João Alberto Steffen; FUCHS, Henri Luiz; SILVA, Gilberto Ferreira. O currículo decolonial: da reflexão à colaboração intercultural. Revista Gestão Universitária, 2019.

PAULINO, Vicente. Currículo nacional de ensino de Timor-Leste como um problema a resolver. In: FONSECA, Sabina da; BAPTISTA, Maria do Céu; Araújo, Irta Sequeira Baris de. Desafios da Educação em Timor-Leste: Responsabilidade social. Unidade de Produção e Disseminação do Conhecimento do Programa de Pós-Graduação e Pesquisa da UNTL,2018.

PAULINO, Vicente. As lendas de Timor e a literatura oral timorense. Anuário Antropológico, Brasília, UnB, v. 42, n. 2, p. 157-179, 2017.

PAULINO, Vicente; APOEMA, Keu. Tradições orais de Timor-Leste. Belo Horizonte: Casa Apoema; Díli - Universidade Nacional Timor-Leste, 2016. 
RAFFESTIN, Claude. E se a representação fosse apenas a invenção da moeda fiduciária do real? Revista Formação. Presidente Prudente: UNESP, v. 2, n. 14, p. 8-13, 2007.

RAMOS, Ana Margarida; TELES, Filipe. Memória das políticas educativas em Timor-Leste: A consolidação de um sistema (2012-2017). Aveiro: Editora da Universidade de Aveiro, 2012.

RDTL, República Democrática de Timor-Leste. Manual do Aluno de Geografia do $1^{\circ}$ ano de escolaridade. Autoras: GOMES, Conceição; MORGADO, Margarida; COELHO, Celeste. Ministério da Educação. Díli, 2012.

RDTL, República Democrática de Timor-Leste. 3 Congresso Nacional da Educação - A Educação é o pilar da consolidação da identidade e Desenvolvimento da Nação. Díli, 2017.

SANTOS, Boaventura de Sousa; MENESES, Maria Paula. Introdução. In: SANTOS, Boaventura de Sousa; MENESES, Maria Paula (Orgs.). Epistemologias do sul. Coimbra: Edições Almedina, 2009.

SANTOS, Milton. Por uma outra globalização: do pensamento único à consciência universal. Rio de Janeiro: Record, 2000.

SANTOS, Milton. O trabalho do geógrafo no terceiro mundo. São Paulo: Editora da Universidade de São Paulo, 2013.

SILVA, Antero Benedito da. Educação e desafios em Timor-Leste pós-colonial. In: GUEDES, Maria Denise. (orgs.)...[et al.] Professores sem fronteiras: pesquisas e práticas pedagógicas em Timor-Leste. Florianópolis: NUP/UFSC, 2015.

SILVA, Antero Benedito da. Educação Timoriana: uma proposta alternativa. In: PAULINO, Vicente Paulino; BARBOSA, Alessandro Tomaz (orgs.) Língua, ciência e formação de professores em Timor-Leste. Dili: Unidade de Produção e Disseminação do Conhecimento e Programa de Pós-Graduação e Pesquisa da UNTL, 2016.

SILVA, Tomaz Tadeu da. Identidades terminais: as transformações na política da pedagogia e na pedagogia da política. Petrópolis: Vozes, 1996.

SOUSA, Lúcio. Educação, manuais e etnocentrismo: os timorenses nos Manuais de Geografia do Ensino Primário Português do Estado Novo. Revista Veritas. v. 1, n. 2, 2013.

SOUZA, Marcelo Lopes de. Práticas Espaciais. In: SOUZA, Marcelo. Os conceitos fundamentais da pesquisa sócio-espacial. Rio de Janeiro: Bertrand Brasil, 2001. 
STRAFORINI, Rafael. Permanências e mudanças no currículo de geografia dos anos iniciais ensino fundamental. Revista Brasileira de Educação em Geografia, Campinas, v. 6, n. 11, p.160-184, jan. /jun., 2016.

TONINI, Ivaine Maria. Geografia Escolar: uma história sobre seus discursos pedagógicos. ljuí: Ed. Unijuí, 2006.

VILELA, Carolina Lima. Livros didáticos e o discurso do conhecimento escolar em geografia: a abordagem regional como regularidade. Revista Brasileira de Educação em Geografia. v. 4, n. 8, p. 55-70, 2014.

WALSH, Catherine. Interculturalidad, Estado, sociedad: luchas (de)coloniales de nuestra época. Quito: Universidad Andina Simón Bolivar, Ediciones AbyaYala, 2009.

Recebido em: 16/05/2021

Aprovado em: 22/06/2021 